Document downloaded from:

http://hdl.handle.net/10251/56831

This paper must be cited as:

Furió, S.; Andrés Romano, C.; Adenso Díaz, B.; Lozano Segura, S. (2013). Optimization of empty container movements using street-turn: Application to Valencia hinterland. Computers and Industrial Engineering. 66(4):909-917. doi:10.1016/j.cie.2013.09.003.

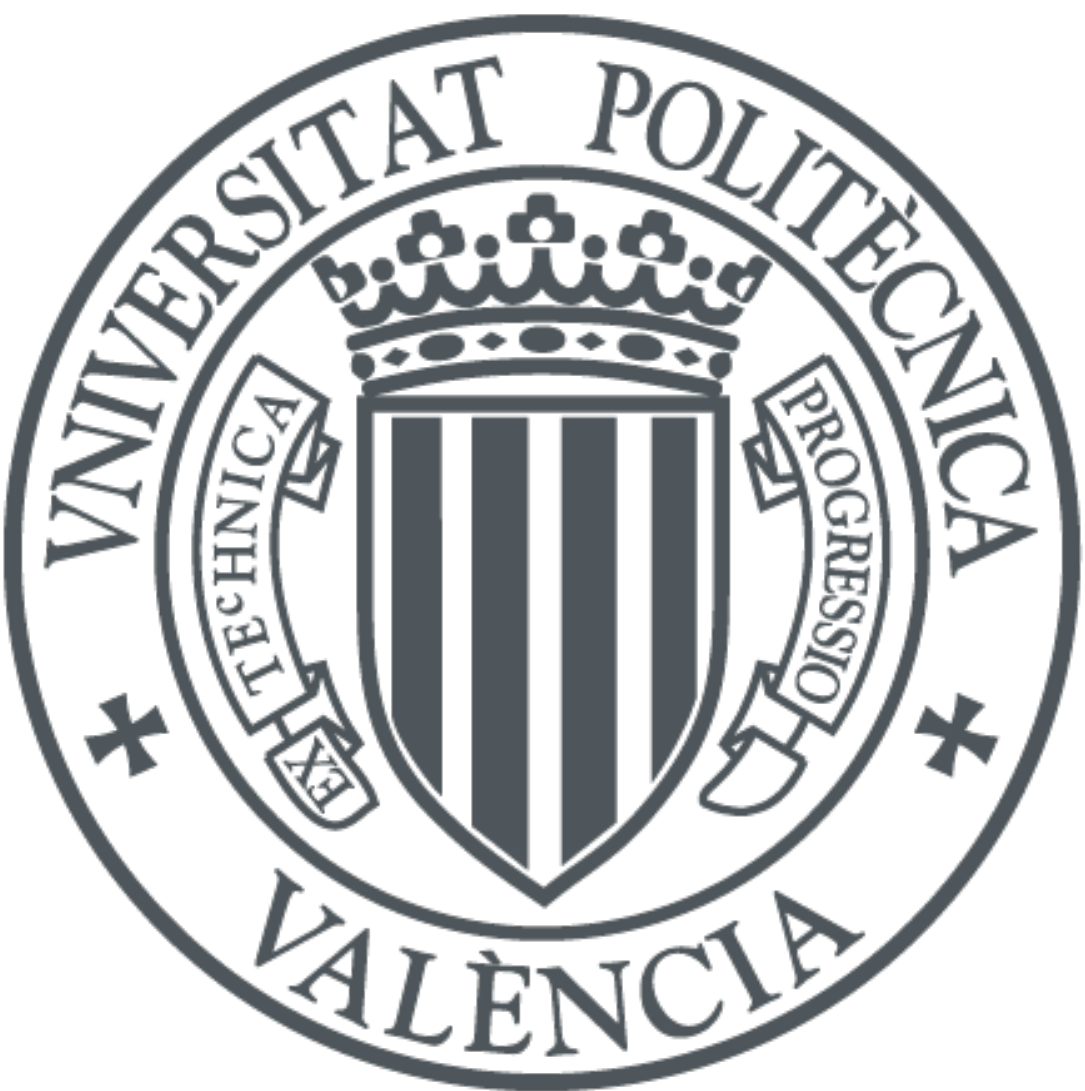

The final publication is available at

Copyright Elsevier

Additional Information 


\section{Optimization of empty container movements using street-turn: Application to Valencia hinterland}

\subsection{Abstract}

Empty maritime container logistics is one of the most relevant costs for shipping companies. In this paper two mathematical models (based on two different container movement patterns, i.e. with and without street-turns) were defined to optimize land empty container movements among shippers, consignees, terminals and depots, along with minimizing storage costs. One of the proposed optimization models was embedded in a simple Decision Support System (DSS) and then tested with real data, based on the operations in Valencia's (Spain) hinterland. The results obtained confirm the benefits of implementing these kinds of models for the company, and additional experiments assess and quantify the advantage of using the more complex approach that is able to implement street-turn patterns.

\subsection{Introduction}

Maritime containers traffic started in the 50s and, since then, has experienced an amazing development, causing a real revolution in international trade and transport. Maritime container traffic has been growing very quickly during the last 15 years with steady annual growth rates of over 10\%, achieving a global port traffic throughput in 2008 of around 400 million TEU (twenty-feet equivalent unit (TEU), is a measurement unit equivalent to a twenty-feet container). 
Modelos y métodos avanzados para la logística del contenedor.

Aplicación al puerto de Valencia

In order to meet this transport demand there is a world fleet of container ships with a capacity of around 10 million TEU. The total capacity of all maritime containers in use is estimated to be around 25 million TEU, mainly owned by shipping and leasing companies. With regard to the type of maritime containers used in all these operations, there is a large variety of equipment (standard, highcube, reefers, platforms, etc.), but standard 20 and 40 feet dry cargo containers are almost $90 \%$ of the total fleet (Dekker, 2009).

It is easy to imagine the complexity of global container logistics, which is focused on achieving efficient container fleet management by minimizing transport costs and maximizing container use. One part of global container logistics is the empty container logistics. This deals with the movement, storage and distribution of empty containers, a process which starts once the container is emptied at the consignee's facilities, and ends when the empty container is positioned to be loaded again at the next shipper's facilities.

Since an analysis of main world container traffic shows important eastbound/westbound differences on main trade routes (Fig. 1), shipping companies tend to unwillingly accumulate a large number of empty containers at several import-dominant ports (mainly in Europe and the USA) which need to be repositioned to different export-dominant ports (mainly in Asia) where they are required (Li, Leug, Wu, \& Liu, 2006).

Given that empty container incidence on main trade routes exceeds $21 \%$ of total traffic (Dekker, 2009), and containers spend more than half of their lifetime stocked or being transported empty to be repositioned (Crinks, 2000), empty container logistics has became one of the most relevant costs for shipping companies (Wang \& Wang, 2007).

This paper presents, and validates in a real hinterland, some mathematical models dealing with the assignment and placement of empty containers based on daily requirements from shippers and consignees. First, in Section two, we shall introduce the main movement patterns that can be found in the management of containers; Section 3 will summarize the main previous works in the literature; Section 4 introduces the two models proposed; 
Figure 7.1: $\quad$ Main container traffic (millions teu) between regions in 2007 (Dekker, 2009)

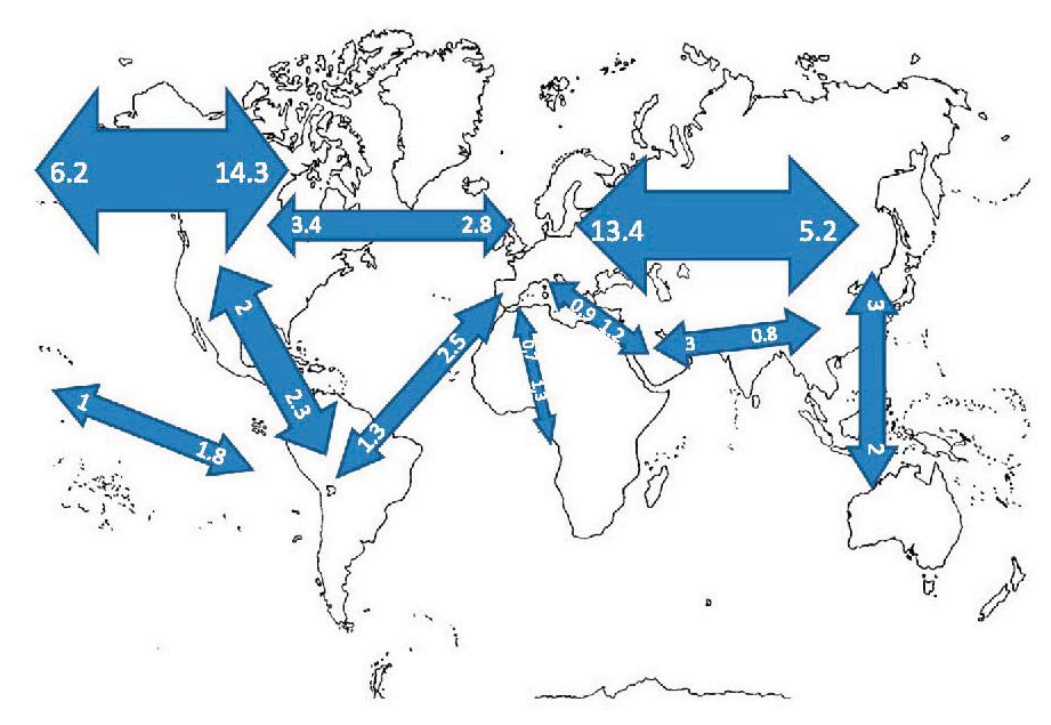

Fuente:

some details and results regarding the application case are presented in Section 5; Section 6 compares both models; the paper finishes with the main conclusions in Section 7.

\subsection{Empty containers' management}

When talking about empty container logistics, two different levels can be considered: international and local or regional (Boile \& Theofanis, 2008). The former has to do with the movement of empty containers on a global scale to reverse the imbalance problem along the main world commercial axes. This is managed directly by shipping companies at a global level, attending to global container surplus and shortage, ships' routes, schedules and free capacity. 
Modelos y métodos avanzados para la logistica del contenedor.

Aplicación al puerto de Valencia

The latter level deals with the inland movement of empty containers between port terminals, empty container depots (where empty containers are temporarily stored), consignees (receiving imported full containers which are emptied there) and shippers (receiving empty containers to be loaded for export). Local maritime agents, who are responsible for the containers' fleet management within their area of influence, manage all these movements (González-Torre, Sarkis, \&t Adenso-Díaz, 2013).

Murty, Liu, Wan, and Linn (2005) briefly explain all the operations related to the movement of containers in a harbour facility. Many decisions are identified in this part of the process (allocation of berths to arriving vessels, allocation of quay cranes, appointment times for external trucks, storage space assignment, yard cranes' deployment, etc.). These authors present a DSS developed for optimizing some of these decisions in one of the busiest container ports in the world, namely Hong Kong.

Fig. 2 shows the different container movement patterns that can be found outside of the harbour. The first pattern presented (labelled A) matches the typical "empty repositioning" operation. It could typically be an Asian import container which reaches a European port, from which it is moved to the importer's facilities to be unloaded (movement 2) and, once emptied, is transported back to the port terminal (movement 3) to be repositioned or sent back empty to Asia (movement 4), in order to start a new cycle. Pattern $B$ is also an empty repositioning operation. The difference is that the empty container is stocked in an empty container depot before being sent back to the port terminal to be loaded onto a ship for repositioning.

Patterns $C$ and $D$ are known as "match back" operations, where a matching export movement means the empty repositioning of the container can be avoided. The difference between $C$ and $D$ is the place where the container is stored before being re-used in an export operation (port terminal for $\mathrm{C}$, and empty container depot for D).

Finally, pattern E is a special match back operation where the container, once unloaded at an importer facility (consignee), is moved directly to the shipper facility (exporter) to be loaded again. This operation, known as "street-turn", is the most interesting option for big container shipping 
companies; however, it is difficult to carry out because it needs a significant level of coordination. The import and export operation requirements must be similar and coincident in time, as well as the type of container, shipping company and place. In addition, most of the time, containers need intermediate operations after a delivery cycle in order to be reused (brushing, cleaning, repairing, etc.). Obviously this is the most efficient type of movement as it saves temporary empty storage.

\subsection{Literature review}

The problem of allocating a storage facility to every empty container supply or demand operation can be modelled as a minimum cost network flow problem. This approach looks for optimal solutions giving responses to the daily operational decisions of local maritime agents, as discussed above. There are a number of previous works in the literature using mathematical modelling to solve the problem of empty container allocation. One of the earliest papers presenting network models for empty container management was published by White (1972). However, the problem received little attention until the end of the 1980s. Braekers, Janssens, and Caris (2011) provide a comprehensive state of art solution to the problem after reviewing the different approaches, some of which are commented on below. Table 1 presents a classification of the existing research based on whether the authors consider deterministic or stochastic/fuzzy data or whether they study the empty container management problem at the global (i.e. multiport) or local (i.e. inland) level.

As can be seen, the majority of the approaches deal with the empty container repositioning problem on a global level and take into account the uncertainty in the demand and supply of empty containers. The basic goal of those studies is to determine the dynamic balance flow repositioning policies.

The inland empty container allocation has been somewhat less studied and for the most part has used deterministic mathematical programming approaches. Thus, Crainic, Dejax, and Delorme (1989) discussed the problem of locating empty vehicles in an inter-city freight transportation system in 
Modelos y métodos avanzados para la logística del contenedor.

Aplicación al puerto de Valencia

Figure 7.2: $\quad$ Container movement patterns

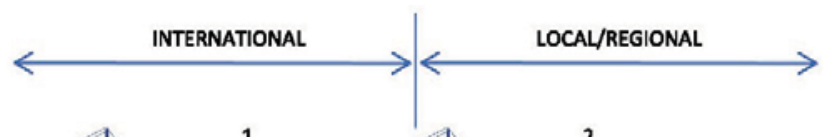

(A)

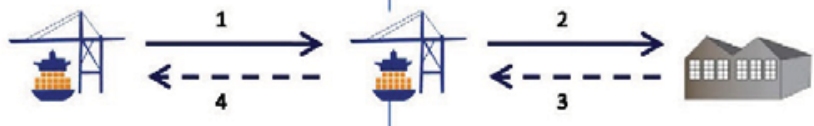

(B)

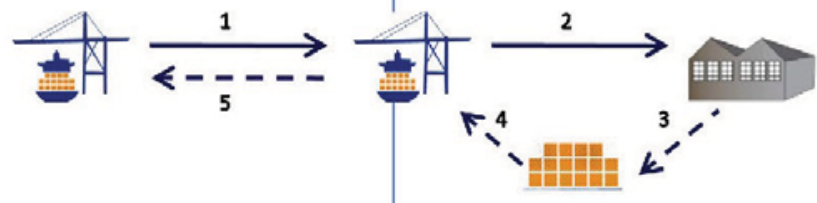

(C)
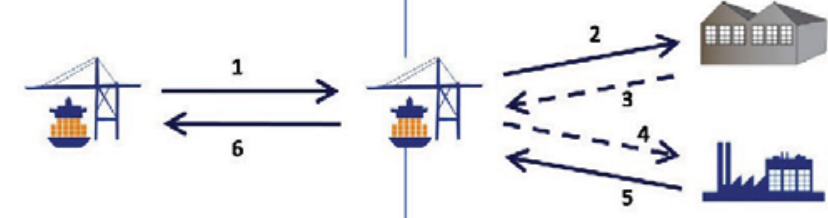

(D)

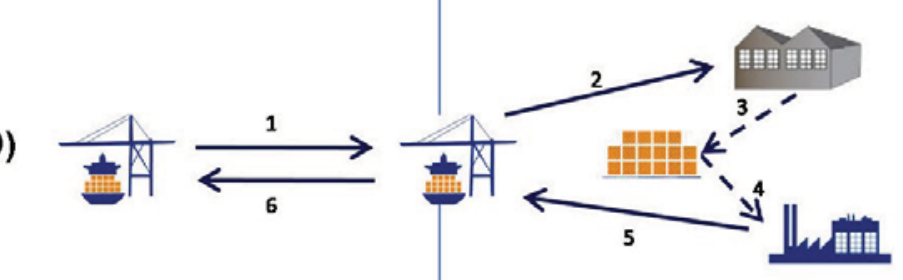

(E)

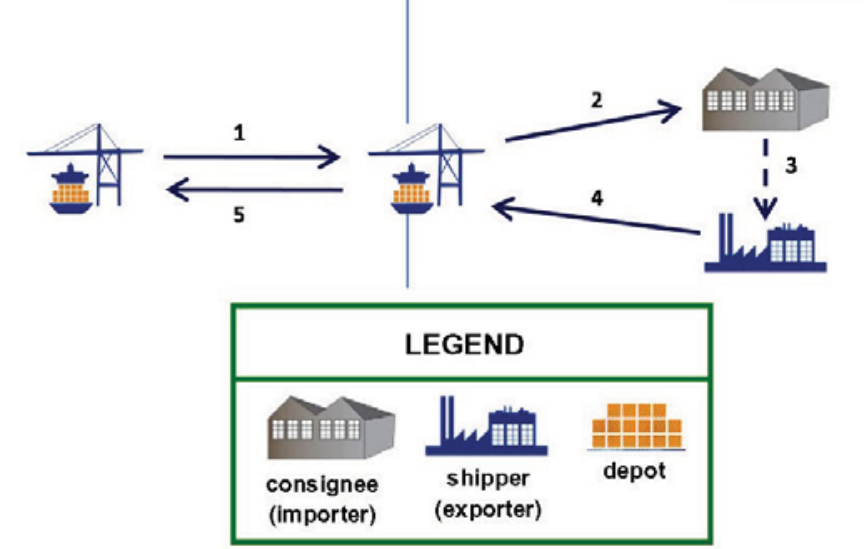

(A) Empty repositioning. (B) Idem with depot. (C) Match-back. (D) Idem with depot. (E) Street-turn (triangulation). Dotted lines represent empty container movements.

Fuente: own elaboration 
order to minimize the cost of depot opening and vehicle transportation, but they did not consider the space-time dependency of events. A more general framework to address the specific characteristics of the empty container allocation problem, in the context of the inland distribution system for an international maritime shipping company, is later presented by Crainic, Gendreau, and Dejax (1993). They developed a mathematical formulation to deal with the uncertain nature of supply and demand but no time dependent costs were taken into account and no experimental results presented. Choong, Cole, and Kutanoglu (2002) developed an integer programming model for the tactical management of a homogeneous fleet of empty containers, subject to meeting requirements for moving loaded containers.

Table 7.1: $\quad$ Classification of existing empty container logistics research

\begin{tabular}{lll}
\hline & Deterministic approach & Uncertainty approach \\
\hline Multi-port & Di Francesco, Manca, Olivo, and & Cheung and Chen (1998) \\
level & Zuddas (2006) & Shen and Khoong (1995) \\
& Wang and Wang (2007) & Di Francesco, Crainic, and Zuddas \\
& Shintani, Imai, Nishimura, and & (2009); Di Francesco, Lai, and \\
& Papadimitriou (2007) & Zuddas (2013) \\
& Bandeira, Becker, and Borenstein & Dong and Song (2009) \\
& (2009) & Wang and Tang (2010) Chou et al. \\
& Hajeeh and Behbehani (2011) & (2010) \\
& & Song and Dong (2011a, 2011b) \\
Single- & White (1972) & \\
port level & Dejax and Crainic (1987) Crainic & Song and Zhang (2010) \\
& et al. (1989) & \\
& Choong et al. (2002) Boros et al. & \\
& (2008) & \\
Braekers et al. (2013) &
\end{tabular}

Source: own elaboration

A model involving both a domestic and a foreign shipping company was studied by Boros, Lei, Zhao, and Zhong (2008). They developed mathemati- 
Modelos y métodos avanzados para la logística del contenedor.

Aplicación al puerto de Valencia

cal models and algorithms to support a collaborative planning and scheduling of container operations for supply chain logistics. Very recently, Braekers, Caris, and Janssens (2013) have formulated the problem of drayage planning as an asymmetric multiple-vehicle Travelling Salesman Problem with Time Windows, solving it using a two-phased deterministic annealing.

To the best of our knowledge, there are no studies that jointly consider the set of features included in the problem formulation of this paper and that compare the corresponding results with the policies of actual shipping companies.

\subsection{Model formulation}

Two different models regarding container assignment decisions have been developed. In the second one, street-turn operations (i.e. direct consignee to shipper movements) are considered. However, the first model is equally interesting, given that real operations in most harbours do not generally consider street-turns (because of the difficulties of their implementation), so it seems reasonable to start with this simpler approach.

The mathematical models presented below minimize the total costs, along a planning horizon, of managing empty containers while satisfying the corresponding demand from shippers, matching it with the supply from consignees and the empty containers that arrive at the port terminals coming from other ports. Total costs include all transportation costs (between terminals, depots, consignees and shippers) plus storage costs (at the depots and at the terminals). The underlying transport network structure involves links between consignees and terminals/depots, between terminals/depots and shippers, and between terminals and depots.

The operation of the system can be described by following a full container that is unloaded at a consignee. That empty container is transported for storage to either a terminal or a depot. On particular occasions, when the proper conditions are met, the empty container could be directly transported to a shipper ready for loading. That is called a street-turn. More 
often, the empty containers required by shippers would be delivered from those stored at the terminals and depots. In addition, to balance the system, some empty containers may need to be imported or exported at the terminals from/to other ports.

Since, as indicated above, there are options when moving the containers (from/to depots or terminals) and since actually there may be several depots and terminals in the area, the proposed approach must compute the most cost-effective allocation of every empty container entering and leaving the system. That is done by computing, for each time period, the empty container flow between the nodes of these transportation networks and the resulting inventories of empty containers at the terminals and depots.

The following assumptions are made:

1. Different types of container are considered.

2. In each time period the number of empty containers of each type generated at a consignee or arriving at any terminal from other ports is known.

3. In each time period the number of empty containers of each type required by shippers and at terminals for export to other ports is known.

4. Empty containers are assumed to be delivered to shippers in the time period in which they are required.

5. Empty container transportation costs are linear.

6. Transportation link capacities are unlimited.

7. Empty containers can only be stored at depots or terminals but not within consignees' or shippers' premises.

8. Depots and terminals have a limited capacity for storing empty containers. In addition, a minimum amount of empty containers of each type stored in each depot, i.e. a kind of safety stock, can be imposed.

9. Empty containers are always ready to be used, i.e. no repairs or discarded containers are required.

Before formulating the mathematical model the required notation is introduced: 
Modelos y métodos avanzados para la logistica del contenedor.

Aplicación al puerto de Valencia

Indexes

$C=1,2, \ldots, C$ Consignees

$S=1,2, \ldots, S$ Shippers

$d=1,2, \ldots, D$ Empty container depots

$j=1,2, \ldots, J$ Port terminal

$t=1,2, \ldots, T$ Time periods

$r=1,2, \ldots, R \quad$ Container types

Demand/supply data

$L_{\text {tsr }} \quad$ Number of type rempty containers to provide to shipper $s$ at $t$ time period

$U_{\text {tcr }} \quad$ Number of type $r$ empty containers supplied by consignee $c$ at $t$ time period

$R_{t i r} \quad$ Number of type rempty containers imported at terminal $j$ at $t$ time period

$O_{t j r} \quad$ Number of type $r$ empty containers exported from terminal $j$ at $t$ time period

Storage capacity data

$I_{j r}^{\max } \quad$ Upper limit of type $r$ empty container stock at $j$

terminal

$\hat{I}_{d r}^{\max } \quad$ Upper limit of type $r$ empty container stock at $d$ depot

$\hat{I}_{d r}^{\min } \quad$ Lower limit of type $r$ empty container stock at $d$ depot

Storage costs data

$h_{j r} \quad$ Unit storage cost of type $r$ empty containers at $j$ terminal

$\hat{h}_{d r} \quad$ Unit storage cost of type $r$ empty containers at $d$ depot

Transport cost data

$\alpha_{c j r} \quad$ Unit transport cost of type $r$ container from consignee $c$ to terminal $j$ 
$\begin{array}{ll}\beta_{c d r} & \begin{array}{l}\text { Unit transport cost of type } r \text { container from consignee } c \\ \text { to depot } d\end{array} \\ \gamma_{j s r} & \begin{array}{l}\text { Unit transport cost of type } r \text { container from terminal } j \\ \text { to shipper } s\end{array} \\ \delta_{d s r} & \begin{array}{l}\text { Unit transport cost of type } r \text { container from depot } d \text { to } \\ \text { shipper } s\end{array} \\ \varepsilon_{j j^{\prime} r} & \begin{array}{l}\text { Unit transport cost of type } r \text { container from terminal } j \\ \text { to terminal } j^{\prime}\end{array} \\ \varphi_{d d^{\prime} r} & \begin{array}{l}\text { Unit transport cost of type } r \text { container from depot } d \text { to } \\ \text { depot } d^{\prime}\end{array} \\ \mu_{j d r} & \begin{array}{l}\text { Unit transport cost of type } r \text { container from terminal } j \\ \text { to depot } d\end{array}\end{array}$

Initial inventories data

$I_{j r}^{0} \quad$ Initial type $r$ container stock at terminal $j$

$\hat{I}_{d r}^{0} \quad$ Initial type $r$ container stock at depot $d$

Variables

$x_{c j r}^{t} \quad$ Number of type $r$ container supplied by consignee $c$ at $t$ time period and allocated to terminal $j$

$z_{c d r}^{t} \quad$ Number of type $r$ containers supplied by consignee $c$ at $t$ time period and allocated to depot $d$

$y_{j s r}^{t} \quad$ Number of type $r$ containers provided to shippers s from terminal $j$ at time period $t$

$w_{d s r}^{t} \quad$ Number of type $r$ containers provided to shippers s from depot $d$ at time period $t$

$v_{j j^{\prime} r}^{t} \quad$ Number of type $r$ containers moved from depot $d$ to depot $d^{\prime}$ at time period $t$

$q_{d d^{\prime} r}^{t} \quad$ Number of type $r$ containers moved from depot $d$ to depot $d^{\prime}$ at time period $t$

$p_{j d r}^{t} \quad$ Number of type $r$ containers moved from terminal $j$ to depot $d$ at time period $t$ 
Modelos y métodos avanzados para la logistica del contenedor.

Aplicación al puerto de Valencia

Figure 7.3: $\quad$ Decision variables associated with empty container movements among the different agents

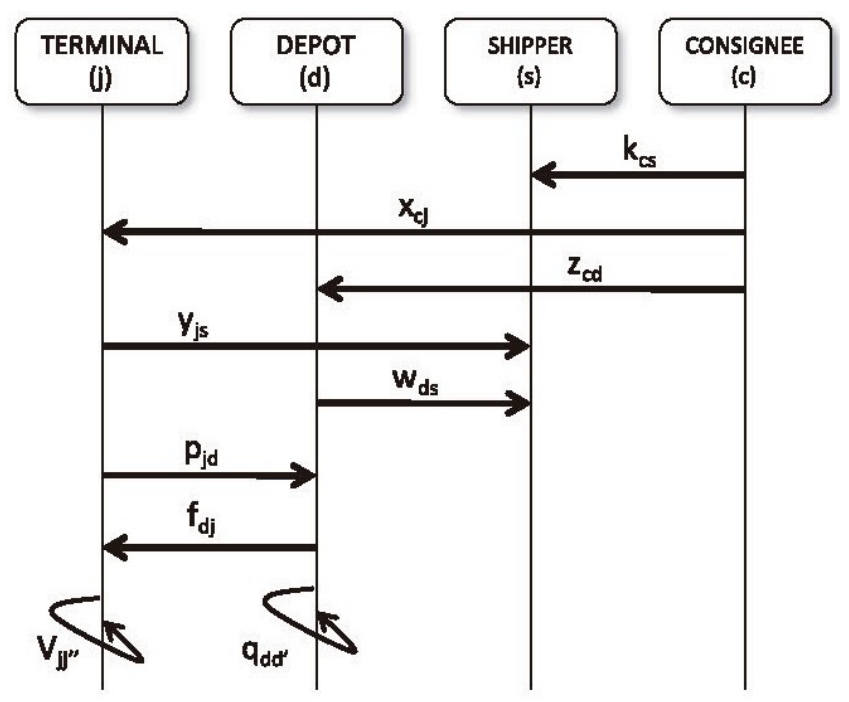

Movements $k_{c s}$ from consignees to shippers (street-turns) are not considered in the basic model

Source: own elaboration

$$
\begin{array}{ll}
f_{d j r}^{t} & \begin{array}{l}
\text { Number of type } r \text { containers moved from depot } d \text { to ter- } \\
\text { minal } j \text { at time period } t
\end{array} \\
I_{j r}^{t} & \begin{array}{l}
\text { Number of type } r \text { empty containers stored at terminal } j \\
\text { and time period } t
\end{array} \\
\hat{I}_{d r}^{t} & \begin{array}{l}
\text { Number of type } r \text { empty containers stored at depot } d \\
\text { and time period } t
\end{array}
\end{array}
$$

Fig. 3 summarizes all the relevant decision variables and what the movement is that each one is capturing. Thus, variables $x_{c j r}^{t}$ (respectively, $z_{c d r}^{t}$ ) represent the flow of empty containers from the consignees, after unloading, to terminals (respectively, to depots). Analogously, variables $y_{j s r}^{t}\left(\right.$ respectively, $w_{d s r}^{t}$ ) represent the flow of empty containers to shippers, 
for loading, from terminals (respectively, from depots). Variables $p_{j d r}^{t}$ and $f_{\text {djr }}^{t}$ capture the movement of empty containers, in both directions, between terminals and depots. Finally, there are movements of empty containers between terminals (variables $v_{j j^{\prime} r}^{t}$ ) and between depots (variables $q_{d d^{\prime} r}^{t}$ ). Fig. 3 also shows variables $k_{c s r}^{t}$ that represent direct movements of empty containers from consignees to shippers. These so-called street-turn movements are very efficient and will be considered as an extension of the basic model.

The basic formulation for the first model (with no "street-turn" operation) is the following:

Minimize

$$
\begin{aligned}
& \sum_{t} \sum_{r}\left[\sum_{c} \sum_{j} \alpha_{c j r} x_{c j r}^{t}+\sum_{c} \sum_{d} \beta_{c d r} z_{c d r}^{t}\right] \\
& +\sum_{t} \sum_{r}\left[\sum_{j} \sum_{s} \gamma_{j s r} t_{j s r}^{t}+\sum_{d} \sum_{s} \delta_{d s r} w_{d s r}^{t}\right] \\
& +\sum_{t} \sum_{r}\left[\sum_{j} \sum_{j^{\prime}} \varepsilon_{j j^{\prime} r} v_{j j^{\prime} r}^{t}+\sum_{j} \sum_{d} \mu_{j d r} p_{j d r}^{t}\right] \\
& +\sum_{t} \sum_{r}\left[\sum_{d} \sum_{j} \lambda_{d j r} f_{d j r}^{t}+\sum_{d} \sum_{d^{\prime}} \varphi_{d d^{\prime} r} q_{d d^{\prime} r}^{t}\right] \\
& +\sum_{t} \sum_{r}\left[\sum_{j} h_{j r} I_{j r}^{t}+\sum_{d} \hat{h}_{d r} \hat{I}_{d r}^{t}\right]
\end{aligned}
$$

subject to

$$
\begin{array}{ll}
\sum_{j} x_{c j r}^{t}+\sum_{d} z_{c d r}^{t}=U_{t c r} & \forall t \forall c \forall r \\
\sum_{j} y_{j s r}^{t}+\sum_{d} w_{d s r}^{t}=L_{t s r} & \forall t \forall s \forall r \\
I_{j r}^{t} \leq I_{j r}^{\max } \quad \forall t \forall j \forall r &
\end{array}
$$




$$
\begin{array}{r}
\hat{I}_{d r}^{\min } \leq \hat{I}_{d r}^{t} \leq \hat{I}_{d r}^{\max } \quad \forall t \forall d \forall r \\
I_{j r}^{t}=I_{j r}^{t-1}+R_{t j r}-O_{t j r}-\sum_{s} y_{j s r}^{t}-\sum_{d} p_{j d r}^{t}-\sum_{j^{\prime}} v_{j j^{\prime} r}^{r} \\
+\sum_{c} x_{c j r}^{t}+\sum_{d} f_{d j r}^{t}+\sum_{j^{\prime}} v_{j^{\prime} j r}^{t} \quad \forall t \forall j \forall r \\
\hat{I}_{d r}^{t}=\hat{I}_{d r}^{t-1}-\sum_{s} w_{d s r}^{t}-\sum_{j} f_{d j r}^{t}-\sum_{d^{\prime}} q_{d d^{\prime} r}^{t}+\sum_{c} z_{c d r}^{t} \\
+\sum_{j} p_{j d r}^{t}+\sum_{d^{\prime}} q_{d^{\prime} d r}^{t} \quad \forall t \forall d \forall r
\end{array}
$$

All variables non-negative (integer).

Regarding the meaning of the constraints, Eq. (1) assures that the number of containers supplied from import operations matches the number of containers sent from consignees to depots and terminals; according to Eq. (2) the number of containers provided for export operations must match the number of containers sent from depots and terminals to shippers: constraint (3) states that empty container stock at terminals should be below the upper limit established and constraint (4) imposes that empty container stock at depots should be between the lower and upper limits established; constraints (5) and (6) represent the empty containers' flow balance equations at container terminals and at empty container depots, respectively.

From an implementation point of view, once tested and validated, the first model can be extended and adapted to allow direct street-turn movements between consignees and shippers, closely matching import and export operations. The second model takes into account the time and type of container needed to match import and export operations, but it does not take into account any other limitations to the triangulation operations, such as required intermediate inspection, cleaning or repairing operations (manual intervention is required in those cases).

Notation for this extended model is the same as for the previous one, although some new variables are necessary in order to consider triangulation 
operations. Thus, variable $k_{c s r}^{t}$ represents the number of type $r$ containers supplied by consignee $c$ at time period $t$ and allocated directly to shipper $s$ to cover an export operation requirement, while cost coefficient $\sigma_{c s r}$ represents the unit transport costs of empty containers of type $r$ between consignee $c$ and shipper $s$. The objective function of the extended model includes the following additional term:

$\sum_{t} \sum_{r} \sum_{c} \sum_{s} \sigma_{c s r} k_{c s r}^{t}$

Furthermore, while constraints (3)-(6) remain, Eqs. (1) and (2)

change as follows:

$$
\begin{array}{ll}
\sum_{j} x_{c j r}^{t}+\sum_{d} z_{c d r}^{t}+\sum_{s} k_{c s r}^{t}=U_{t c r} & \forall t \forall c \forall r \\
\sum_{j} y_{j s r}^{t}+\sum_{d} w_{d s r}^{t}+\sum_{c} k_{c s r}^{t}=L_{t s r} & \forall t \forall s \forall r
\end{array}
$$

\subsection{Application to the case of Valenciaport}

The Port Authority of Valencia (Spain), commercially known as Valenciaport, manages the three state-owned ports of Valencia, Sagunto and Gandia which are located along $80 \mathrm{~km}$ of Spain's Eastern Mediterranean coastline. The Port of Valencia is the most important port in Spain from a commercial viewpoint, ranking first in the country's port system for registered foreign trade container volume (imports + exports). The Port of Valencia's main strength lies in its container traffic which exceeded 3.6 million TEU in 2009, ranking the first in the Mediterranean and the fifth in Europe. Valenciaport is a good choice for shipping lines due to its hinterland (51\% of Spanish GDP and half of Spain's working population lie within a radius of $350 \mathrm{~km}$ ). Moreover, Valenciaport's privileged geostrategic situation in the centre of the Western Mediterranean coastline, in line with the east-west shipping corridor crossing the Suez Canal and the Strait of Gibraltar, positions it as the first and last port of call for the main regular line shipping companies sailing between America, the Mediterranean Basin and 
Modelos y métodos avanzados para la logística del contenedor.

Aplicación al puerto de Valencia

the Far East. As a hub port for the Western Mediterranean, Valenciaport enables goods to be efficiently distributed over a radius of $2000 \mathrm{~km}$, not only in Southern EU countries but also in North Africa. It is for these reasons that the main world container shipping lines operate in the Port of Valencia.

Regarding the problem of land empty container movements, there is a fleet of around 3000 container trucks operating around the Port of Valencia and covering annually more than 215 million $\mathrm{km}$, half of them with empty containers. Just a $10 \%$ reduction in empty container truck movements could save more than $€ 7$ million. The continuous increase in the port's container traffic (with yearly average growth rates of over 10\%) and forecasted port extension (which will double the container terminals' capacity) make it necessary to rationalize truck movements by reducing empty movements and fostering alternatives such as rail transport.

China Shipping is one of the largest shipping groups in Asia and it has operated in Spain and the Port of Valencia since 1999, offering regular services for Atlantic Europe and the Baltic Sea, the Mediterranean and Black Sea, as well as the Middle and Far East. Yearly traffic for the China Shipping-Spain Agency in the Port of Valencia has been in recent years about 80,000 TEU, with a significant imbalance towards import operations. This means more than 250 land truck transport services per day and more than $60,000 \mathrm{~km}$ covered daily, half of them with an empty container. Just a 10\% reduction of land empty container movements for this company could lead to a reduction in truck transport costs near to $€ 2000$ per day (Furio, Monfort, Sapiña, Esquembre, \& Torregrosa, 2007), even though, due to the difficulties of reducing empty container movements and the scope of the project, the initial objective when the company decided to implement a Decision Support System for empty containers management was to achieve a modest daily saving of around $€ 500$.

\subsubsection{Specific problem statement}

An analysis of empty containers operations and management at the Valencia Branch Office of China Shipping-Spain showed that the company had well defined procedures to retrieve and share updated information, and 
have control of the equipment (containers), but there was a lack of operating tools to support any decisions made regarding minimizing movements and storage and transportation costs.

Empty containers storage and allocation decisions were made as transport orders arrived, trying to maintain a balanced inventory at the different empty container depots. However, there was no further analysis in order to find synergies between different operations or transport orders and to try to reduce transport and storage costs.

The proposal was to define a Decision Support System based on a mathematical optimization model to support maritime agents' decisions about container movements in order to achieve reduced costs for container fleet management. It is important to state that only daily operational decisions will be considered, as other strategic decisions such as the selection of the container terminals and empty container depots to work with are outside the scope of this paper. These kinds of decisions are considered as a given input to the problem which is addressed here.

Therefore the daily operational decisions of the local maritime agent concerning empty container logistics were the selection, for every export operation of empty container providers from different terminals and empty depots (or consignees in the case of 'street-turn' services matching import and export operations). Other decisions were the selection of empty containers' final destination for every import operation, and the selection and distribution of container movements among different storage places (terminals and empty container depots).

As initial goals to determine how to make all these decisions, we tried to ensure empty container availability to fulfill export requirements and to minimize land empty container movements, empty container storage costs, and empty container inventories at port terminals in order to reduce their congestion and improve their productivity.

The minimization of transportation costs is directly related to the minimization of land empty container movements and total cost minimization (transport costs plus storage costs). To ensure empty container availability, a minimum inventory of each type of container is defined depending on 
Modelos y métodos avanzados para la logística del contenedor.

Aplicación al puerto de Valencia

demand forecasts. Optimization of ships' capacity utilization is approached by estimating the number of empty containers of each type for export (taking into account ship load situation at arrival, ship loading and unloading forecasts, specific instructions of the shipping company). This was considered as given input data established at a higher decision level by the shipping company. The same occurs with the empty containers of each type that are imported at each terminal. Their number is given and follows the company global container flow balancing policy.

\subsubsection{Some experiences of use}

In order to integrate the model with the daily operations of the company, a simple DSS was developed; this assisted the operations manager when deciding about the container movements. As in any DSS, there are three main components to be defined. First, the database component that will feed the model component with current and updated data must be designed. According to the defined model, the required input data are:

- Ship or line-services arrival forecasts: Date of arrival at port, ship load situation at arrival, loading/unloading movements forecast.

- Empty container inventory position by type of container at different storage facilities (terminal and depots).

- Export and import operations forecast related to ships or lineservices involved.

- Storage costs of empty container at different terminals and depots (these costs are dependent on the number of days containers are stocked).

- Transport costs of moving containers between terminals, shippers, consignees and storage facilities.

Therefore we can find seven tables in the database, which include the following information:

- Port terminals and empty container depots' master files.

- Shippers' and consignees' master files.

- Type of containers' master file.

- Historic data of transport operations associated with different 
- Line services.

- Ships' arrival forecasts.

- Road transport costs information.

- Storage costs information.

Since the shipping company information system holds all these data in different formats, an option was included in order to import and translate the necessary information into the internal format of the DSS.

As has already been stated, the model defined addresses a minimum cost network flow problem where all the decision variables are integer. The resulting integer programming (IP) programme can successfully be solved using a freeware LP solver (and a Java code to generate the model ready to be used). Since all the empty container supplies and demands ( $L_{t s r}, U_{t c r}, R_{t j r}$ $\mathrm{O}_{\mathrm{tir}}$ ) are integer, the optimal solution will have integer values for all the variables, avoiding the necessity of explicitly defining the integer nature of the variables.

Regarding the user interface component, a Visual Basic application was coded to allow all the data gathering operations (connecting to the shipping company central computer), model launching, and output reports. The main output provides a printout, for each day in the planning horizon, with each recommended container movement, showing the point of origin, destination (depot or port terminal), and type of container to be moved. All transport operations appear classified by the type of container movement pattern.

It is too complex to compare, for a different number of periods, the savings of the basic model versus the real cost in ordinary daily operations. Just as an example of the performance of our basic model in a real setting, we have taken a random sample of two weeks in the daily operation of the shipping company in Valencia hinterland. In this instance, the agents involved included 205 shippers, 16 consignees, 3 depots and 4 types of container. Real operations in that period to fulfil the required movements, not using the model, amounted to a total of $€ 947,911$. With those data, we ran our basic model obtaining, after a $7.5 \mathrm{~s}$ calculation, a solution whose total cost was $€ 939,774$ (i.e., a saving of $0.85 \%$ ). 
Modelos y métodos avanzados para la logistica del contenedor.

Aplicación al puerto de Valencia

Although street-turn operations were not carried out on site at the time the DSS was developed, we considered this possibility in order to show the company the potential savings to be obtained. This practice would also reduce the need for empty container movements between different storage facilities. As a typical example of 'street-turn' transport, matching an import operation with its destination in Madrid as recommended by the system, with an export operation with its origin at the city of Tarancón, would generate savings of around $€ 200$ by joining both operations instead of planning two different movements. However, a deeper analysis comparing both patterns needs to be explored in order to understand what further policies to carry out.

\subsection{Street-turn vs. basic model: some experimental re- sults}

Although the optimization of empty container movements in a hinterland could mean significant savings when compared with real operations, the possibility of performing street-turns could bring further benefits to the logistics of the shipping company. In order to assess the benefits of triangulations, we have performed a series of experiments, based on the parameters of the real operation in Valencia port, and solved each case using our two models for comparing the minimum costs computed by both models. Our experimental framework considers three factors, each one with two levels:

- The length of the time horizon (2 or 8 weeks).

- The number of consignees and shippers (one factor level as in the real case above, i.e. 205 consignees and 16 shippers, and another factor level representing a smaller environment with fewer opportunities of connection having half of those, i.e. 102 consignees and 8 shippers, respectively).

- The demand level (one factor level involves the same probability of demand as in the real case commented on above, while the second factor level represents a busier scenario with the double probability of demanding any number of containers). 
With five replications for each factor level combination, the number of instances to solve are therefore $2 \times 2 \times 2 \times 5=40$. The total cost for each instance using both models, with and without street-turn, were computed and recorded. The Wilcoxon signed rank test confirms $(p \approx 0)$ that the difference of the medians of both cost variables is not zero, and therefore a significant effect on costs is confirmed. To avoid the effect of absolute values when comparing different numbers of containers transported, we consider the ratio of the cost given by the basic model (no street-turns) versus the cost given by the model with street-turns allowed. This response ratio varies between 1.014 and 1.077, with a median of 1.039 and an average value of 1.042. Therefore, not using triangulation seems to suppose an extra cost of around $4 \%$ of the logistics costs.

When plotting both costs (Fig. 4) a linear relationship between them can be clearly identified. To find a more accurate calculation of the savings, a linear regression cost_with $=\beta_{0}+\beta_{1}$ cost_without $+\varepsilon$ confirms the relationship, showing a significant coefficient $\beta_{1}=0.9816\left(p \approx 0, r^{2}=0.9999\right)$. Common requirements of normality of the residuals and homoscedasticity are fulfilled. This indicates that a saving of $1.84 \%$ can be obtained when streetturn is performed. The Mann-Whitney test also confirms ( $p \approx 0 ; p=0.002$; $p=0.007$ resp.) that the three factors have an impact on the savings obtained.

It is also interesting to note that in most of the cases that have been tested for both models, the optimal solutions computed do not include movements between depots and terminals (i.e. variables $p_{j d} ; f_{d j ;} ; v_{j j} ; q_{d d^{\prime}}$ are all zero in the optimal solution), which seems logical, given that the main component of the objective function is minimizing transport costs. These kinds of movements would only appear in the optimal solution if upper stock limits were going to be exceeded (i.e. in order to avoid that excess), if there are very high storage costs at any terminal or depot, or if there are specific and large demands for containers at a particular terminal. 
Modelos y métodos avanzados para la logistica del contenedor.

Aplicación al puerto de Valencia

Figure 7.4: $\quad$ Plot of total logistic costs with and without street-turns

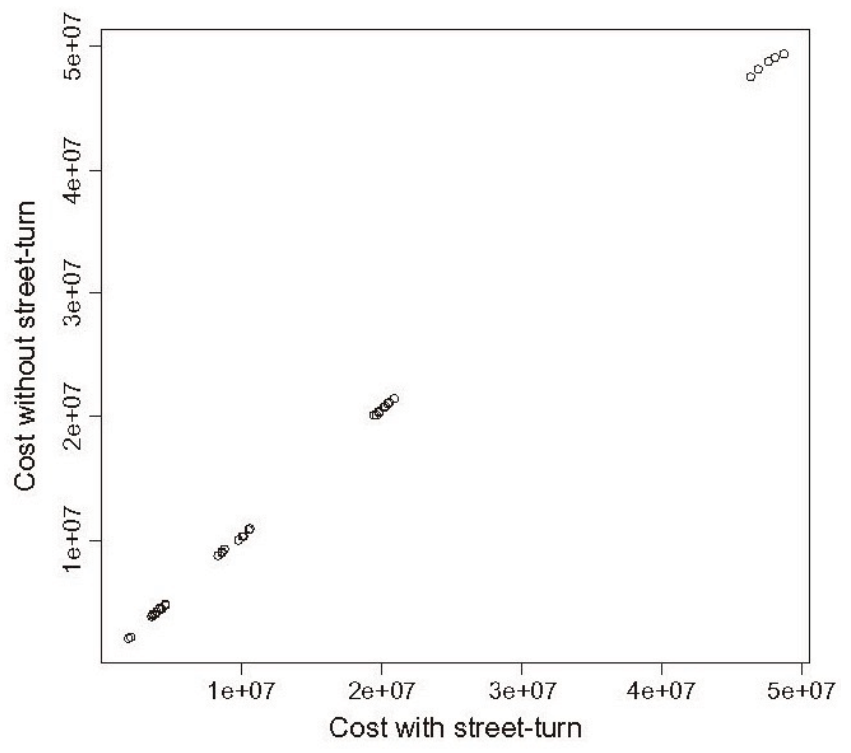

Source: own elaboration

\subsection{Conclusions}

This paper presents an approach to inland empty container logistics network management, identifying different issues and goals (optimizing land movements, optimizing containers' use, optimizing storage yards' use, etc.), as well as different solutions or ideas to be developed and implemented. A mathematical model has been proposed to face empty container assignment in connection with surface transport and container equipment management by local maritime agents.

Results confirm the economic benefits of implementing this kind of model for operational decision making, mainly when street-turn is considered, with savings reaching up to $2 \%$ of total costs when compared with no triangulation. In the case of the China Shipping agency in Valencia, savings could reach up to $€ 200$ per movement for some specific examples. At the end of the year this could be translated into significant cost savings aligned 
with the initial expected objectives. With the development of a good forecast procedure, using historical data and their embedding in the DSS, a significant reduction has also been estimated in empty container transfer movements between depots and terminals by applying the model results.

Another significant advantage of using the developed DSS is that the decisions in container management are less based on the personal experience of the staff working in this area. This provides greater flexibility to the maritime agent and reduces the dependency on specific persons or profiles. Due to the general approach to the empty container logistics problem for local maritime agents, the DSS developed here can be easily transferred to other maritime agents with slight changes to customize or adapt the system to their singularities.

Finally, future research lines on empty container logistics can be pointed out, such as: modelling empty container logistics involving collaborative schemes among shipping lines; modelling container logistics and traffics introducing the "risk" concept; modelling international container traffic and different scenarios of container fleet composition; development of useful models to design new infrastructures to support container logistics; and, development of new technologies to improve land use at container yards.

\subsection{Acknowledgments}

This research has been funded by the Spanish Ministry of Science and Innovation through Grant DPI2010-16201 and FEDER.

\subsection{References}

BANDEIRA, D. L., J. L. BECKER y D. BORENSTEIn (2009): "A DSS for integrated distribution of empty and full containers", Decision Support Systems, n. 47(4), p. 383

BOILE, M. P., y S. TheOfANIS (2008): "Empty marine container logistics: Facts, issues and management strategies", GeoJournal, n. 74, pp. 51-65 
Modelos y métodos avanzados para la logistica del contenedor.

Aplicación al puerto de Valencia

BOROS, E., L. LEI, Y. ZHAO y H. ZHONG, (2008): "Scheduling vessels and container-yard operations with conflicting objectives", Annals of Operations Research, n. 161, pp. $149-170$

BRAEkers, K., A. CARIS y G. K. JANSSENS (2013): "Integrated planning of loaded and empty container movements», OR Spectrum, n. 35(2), pp. 457-478

BRAEKERS, K., G. K. JANSSENS y A. CARIS (2011): "Challenges in managing empty container movements at multiple planning levels», Transport Reviews, n. 31, pp. $681-708$

Cheung, R. K., y C. Chen (1998): "A two-stage stochastic network model and solution methods for the dynamic empty container allocation problem», Transportation Science, n. 32, pp. 142-162

Choong, S. T., M. Cole y E. Kutanoglu (2002): «Empty container management for intermodal transportation networks», Transportation Research Part E, n. 38, pp. $423-438$

Chou, C. C., R. H. Gou, C. L. TSAI, M. C. Tsou, C. P. Wong y H. L. YU, (2010): «Application of a mixed fuzzy decision making and optimization programming model to the empty container allocation», Applied Soft Computing, n. 10(4), p. 1071

Crainic, T. G., P. DejaX y L. Delorme (1989): «Models for multimode multicommodity location problems with interdepot balancing requirements", Annals of Operations Research, n. 18, pp. 279-302

Crainic, T. G., M. Gendreau y P. Dejax (1993): «Dynamic and stochastic models for the allocation of empty containers", Operations Research, n. 41, pp. 102-126

CRINKS, P. (2000): Assets management in the global container logistic chain. International Assets Systems

DEJAX, P. J., y T. G. CRAINIC (1987): "A review of empty flows and fleet management models in freight transportation», Transportation Science, n. 21(4), pp. 227-247

DEKKER, N. (2009): Annual container market review and forecast 2009/10. London, Drewry Shipping Consultants Ltd.

Di Francesco, M., T. Crainic y P. ZUddas (2009): «The effect of multi-scenario policies on empty container repositioning" Transportation Research Part E: Logistics and Transportation Review, n. 45, 758-770 
Di Francesco, M., A. MancA, A. Olivo y P. Zuddas (2006): «Optimal management of heterogeneous fleets of empty containers» in Proceedings of international conference on information systems, logistics and supply chain, Lyon, France, pp. 922-931

DI FRANCESCO, M., M. LAI y P. ZUdDAS (2013): "Maritime repositioning of empty containers under uncertain port disruptions", Computers \& Industrial Engineering, n. 64(3), pp. 827-837

DONG, J. X., y D. Song (2009): "Container fleet sizing and empty repositioning in liner shipping systems", Transportation Research Part E: Logistics and Transportation Review, n. 45(6), pp. 860

Furio, S., A. Monfort, R. SAPIÑA, J. Esouembre y A. TORregrosa (2007): Situación Logística del Sector de Transporte Terrestre de Contenedores en el Puerto de Valencia, Aspectos Jurídicos y Económicos del Transporte: Hacia un transporte más seguro, sostenible y eficiente (Tomo 2), Puerto de Valencia, Spain

GonZÁlez-Torre, P., J. SARKIS y B. AdenSO-DíAz (2013): "Shipping agents and container management: An exploratory analysis of infrastructural and cost concerns", International Journal of Shipping and Transport Logistics, n. 5(3), pp. 322-349

HajeEH, M., y W. Behbehani (2011): "Optimizing empty containers distribution among ports", Journal of Mathematics and Statistics, n. 7, pp. 216-221

LI, J. A., S. C. H. LEUG, Y. WU y K. LIU (2006): «Allocation of empty containers between multi-ports», European Journal of Operations Research, n. 182, pp. 400-412

MURTY, K. G., J. LIU, Y. W. WAN y R. LINN (2005): "A decision support system for operations in a container terminal», Decision Support Systems, n. 39(3), pp. 309-332

SHEN, W. S., y C. M. KHOONG (1995): "A DSS for empty container distribution planning", Decision Support Systems, n. 15(1), pp. 75-82

SHINTANI, K., A. IMAI, E. NISHIMURA y S. PAPAdIMITRIOU (2007): "The container shipping network design problem with empty container repositioning", Transportation Research Part E: Logistics and Transportation Review, n. 43, pp. 39-59

SonG, D. P., y J. X. Dong (2011a): «Effectiveness of an empty container repositioning policy with flexible destination ports», Transport Policy, n. 18(1), pp. 92-101 
Modelos y métodos avanzados para la logistica del contenedor.

Aplicación al puerto de Valencia

Song, D. P., y J. X. DONG (2011b): «Flow balancing-based empty container repositioning in typical shipping service routes», Maritime Economics \& Logistics, ก. 13(1), p. 61

SONG, D. P., y Q. ZHANg (2010): "A fluid flow model for empty container repositioning policy with a single port and stochastic demand", SIAM Journal on Control and Optimization, p. 48(5), p. 3623

WANG, B., y G. TANG (2010): "Stochastic optimization model for container shipping of sea carriage", Journal of Transportation Systems Engineering and Information Technology, n. 10(3), pp. 58-63

WANG, B., y T. WANG (2007): "Research on the optimization of intermodal empty container reposition of land-carriage», Journal of Transportation Systems Engineering and Information Technology, n. 7, pp. 29-33

WHITE, W. W. (1972): «Dynamic transhipment networks: An algorithm and its application to the distribution of empty containers», Networks, n. 2(3), pp. 211-236 